\title{
Control of a wind farm based on synchronous generators with a central HVDC-VSC converter
}

\author{
Oriol Gomis-Bellmunt, Member, IEEE, Adrià Junyent-Ferré, Student Member, IEEE, Andreas Sumper, \\ Member, IEEE, and Joan Bergas-Jané, Member, IEEE
}

\begin{abstract}
A control scheme for wind farms based on synchronous generators connected to a single power converter is presented. The scheme is applicable to HVDC interfaced offshore or remote wind farms. The proposed control scheme is based on computing the optimal wind farm electrical frequency depending on the different incoming wind speeds. The power converter regulates the system frequency by adjusting the power injected to the HVDC circuit. Fault ride-through is also possible by reducing rapidly the injected active power. The proposed scheme is validated by means of simulations with a wind farm composed of four wind turbines.
\end{abstract}

Index Terms-Wind power generation, High voltage direct current (HVDC), Variable frequency wind farm, Offshore wind power.

\section{INTRODUCTION}

Onshore wind farms are nowadays capable of not only generating power, but provide support to the grid where they are connected providing ancillary services [1] or contributing to power system stability [2] while riding through faults in the grid [3], [4]. Onshore wind farms can actually be considered as wind power plants as they can be operated as conventional power plants [5].

Remote and offshore wind farms need HVDC or HVAC lines to interface them to the main grid [6]. Above a certain critical distance, HVDC technology stands as the appropriate solution, which can be based on Line Commutated Converters HVDC-LCC [7]-[9] or Voltage Source Converters HVDCVSC [10]-[12]. In both cases, HVDC systems require a power converter at the connection point of the wind farms, allowing a centralized control for the whole wind farm. Some offshore wind farms employ only this central power converter with squirrel cage induction generators [13] or synchronous generators [14], [15], while others combine a central power converter with individual converters and doubly fed induction generators [12] in each wind turbine.

Jovcic [14], [15] proposed a variable frequency wind farm grid to maximize power generation, based on the approach of [16], which is well demonstrated for a single wind turbine: applying a power reference $P^{*}=K \omega^{3}$ or the equivalent

This work was supported by the Ministerio de Ciencia e Innovación under the project ENE2009-08555.

The authors are with Centre d'Innovació Tecnològica en Convertidors Estàtics i Accionaments (CITCEA-UPC), Departament d'Enginyeria Elèctrica, Universitat Politècnica de Catalunya. ETS d'Enginyeria Industrial de Barcelona, Av. Diagonal, 647, Pl. 2. 08028 Barcelona, Spain Tel: +34 934016727, Fax: +34 934017433, e-mail: oriol.gomis@upc.edu. Oriol GomisBellmunt and Andreas Sumper are also with Catalonia Institute for Energy Research IREC. torque reference $T^{*}=K \omega^{2}$ [17], [18] with the appropriate constant $K$, the wind turbine generation is maximized. This approach is broadly used for maximum power point tracking of a single wind turbine controlled by a dedicated power converter. However, the performance of this approach is not demonstrated for a wind farm with multiple wind turbines and a single power converter, when the different wind turbines are generating at different wind speeds. Other authors [13] proposed methods to dynamically search the maximum generation by changing frequency and observing power changes, but these methods present the drawback of possible operation at local maximums, that may generate much less power than an absolute maximum in certain cases. Therefore, the mentioned approaches do not guarantee maximum power generation for all wind speeds in the case of a wind farm connected to a single power converter. The present work proposes a technique to assure maximum power extraction in an offshore wind farm based on synchronous generators connected to a single power converter. Maximum generation power is obtained by computing the optimal wind farm grid electrical frequency depending on the measured wind speeds in all the wind turbines. A frequency controller is implemented to obtain the optimal frequency by adjusting the power converter power. It is important to stress that the term maximum generation power, used throughout the paper, means maximum generation for the chosen topology, i.e. wind farm connected to a single power converter. It is clear that the only possible way of getting all the available power is using dedicated converters for each machine.

Offshore wind farms connected by means of HVDC have to reduce power rapidly when faults onshore occur in order to prevent overvoltages in HVDC circuits. Moreover, this has to be done without using fast communication systems to assure system reliability. Several solutions have been proposed recently [19], [20], including the use of braking resistors to dissipate the power, wind farm frequency increase to reduce power generation letting the wind turbines accelerate, wind farm voltage reduction or directly reducing the power in the converter. Although, the last method is usually not convenient to avoid current and voltage transients in the operation mode switching, the present work achieves fault ride-through by reducing directly the power in main HVDC-VSC converter. This is possible without important transients because the proposed control scheme is based on controlling directly the power in the HVDC-VSC and therefore no operation mode change is required to reduce the power injected in the HVDC circuit. 
The present work presents a control scheme for wind farms (or clusters or wind turbines inside a wind farm) with wind turbines based on synchronous generators connected to a single HVDC-VSC converter. The configuration can be used for HVDC connections (with an already existing HVDCVSC converter) and also with full power back to back power converters. The main advantage of the proposed configuration is that no power converters are required in the individual wind turbines and therefore cost is reduced and reliability is increased. The drawbacks include the lost of part of the wind energy when wind speeds are different (discussed in Section II), the need for auxiliary power converters to supply auxiliary equipment in the wind turbines and the more reduced control capability over the wind turbine mechanical system, compared to the use of individual power converters.

The proposed control scheme can be used both with permanent magnet synchronous generators (PMSG) and wound rotor synchronous generators (WRSG). For PMSG, the generator flux is created by a rotating magnet and therefore individual wind turbines are not capable of controlling it. For WRSG, the flux can be controlled adjusting the rotor current, however for the present work a constat rotor current is assumed and therefore the behavior of both PMSG and WRSG wind farms would be equivalent. The control scheme operates the wind farm to maximize power generation in normal conditions and reduces the power injection when a fault onshore occurs. The proposed scheme has been validated by means of simulations.

The paper is organized as follows. In Section II the convenience of the wind farm grid with a single power converter is discussed considering wind speed variability in wind farms. In Section III the optimum electrical frequency search procedure is described. Section IV analyzes electrically the proposed scheme. The proposed control scheme is introduced in Section $\mathrm{V}$ and simulated in Section VI. The conclusions are summarized in Section VII.

\section{COMPARISON OF THE POWER EXTRACTED BY A WIND} FARM WITH A SINGLE CENTRAL POWER CONVERTER AND INDIVIDUAL CONVERTERS IN EACH WIND TURBINE

Wind variability in wind farms is difficult to analyze in a general way, since it depends heavily on wind turbine locations and incoming wind directions. However, it is possible to undergo a statistical analysis in order to evaluate the effect of wind variation in terms of maximum available power considering the use of a single converter for the whole wind farm or dedicated converters for each wind turbine.

The present section uses an evaluation methodology to evaluate the wind power generated using the three following concepts:

- A Wind farm with a single power converter and variable frequency

- B Wind farm with constant frequency $(50 \mathrm{~Hz})$

- C Wind farm with individual power converters in each wind turbine

The evaluation methodology consists in a massive analysis of different scenarios in order to extract conclusions about the amount of power generated by the different concepts. The methodology is based on a two-level approach:
- In the first level a set of wind speeds is generated. According to the data provided by means of Weibull distribution parameters, the average wind farm wind speed is generated randomly. With this average value and the typical deviation the individual wind turbines speeds are generated randomly using a Normal distribution. The different wind speeds sets are generated $N_{\text {sim }}$ times for different $N_{s d}$ standard deviations values to be analyzed. Therefore a total number of $N_{s i m} \times N_{s d}$ wind speeds set are generated.

- In the second level, the generated power for the different configurations is analyzed. Each wind speeds set is analyzed for different electrical frequencies: for a given wind speeds set, a sweep of $N_{\text {freq }}$ electrical frequencies is undergone, calculating for each of them the equilibrium point and the electrical power generated. As a result of the analysis the following total powers are computed: maximum available power $P_{c p}$ (only obtained using individual power converters in each wind turbine), maximum power using a single power converter with variable frequency $P_{p c}$ and power generated with a constant frequency grid (50 Hz) $P_{50}$. Summing the powers obtained for the $N_{\text {sim }}$ simulations, the ratios $\alpha_{p c}=\sum P_{p c} / \sum P_{c p}$ and $\alpha_{50}=\sum P_{50} / \sum P_{c p}$ are calculated for each different standard deviation.

The methodology has been applied to the wind farm described in the Appendix, considering a Weibull distribution data from [21], [22] $(\mathrm{a}=9.02, \mathrm{~b}=2.26)$ and different standard deviations between 0.5 and $10 \mathrm{~m} / \mathrm{s}\left(N_{s d}=20\right)$. The simulations have been performed with $N_{\text {freq }}=100$ and $N_{\text {sim }}=200$. The results are shown in Fig. 1. Initially, for a standard deviation of $0.5 \mathrm{~m} / \mathrm{s}, \alpha_{p c}$ is 0.9979 and $\alpha_{50}$ is 0.802. Therefore for low standard deviations (similar wind speeds throughout the wind farm), the performance of the single power converter with variable frequency is excellent. When the standard deviation is increased the performance of both single power converter based methods is decreased due to the larger wind speed variability, however the single power converter with variable frequency concept maintains $\alpha_{p c}$ above 0.95 until the standard deviation is larger than $2.5 \mathrm{~m} / \mathrm{s}$, which is larger than typical values of less than $1 \mathrm{~m} / \mathrm{s}$ [23]. Even for a huge standard deviation of $10 \mathrm{~m} / \mathrm{s}$, the value of $\alpha_{p c} 0.7827$ is acceptable. In all the cases, the performance of the single power converter with variable frequency is between 0.19 and 0.38 better than the constant frequency grid.

Similar analysis for wind farms with different number of wind turbines shows similar results. For 10 wind turbines, with standard deviation of $2 \mathrm{~m} / \mathrm{s}, \alpha_{50}$ is 0.75 and $\alpha_{p c} 0.95$. With standard deviation of $5 \mathrm{~m} / \mathrm{s}, \alpha_{50}$ is 0.57 and $\alpha_{p c} 0.82$. For 20 wind turbines, with standard deviation of $2 \mathrm{~m} / \mathrm{s}, \alpha_{50}$ is 0.71 and $\alpha_{p c} 0.94$. With standard deviation of $5 \mathrm{~m} / \mathrm{s}, \alpha_{50}$ is 0.55 and $\alpha_{p c} 0.8$. For larger number of wind turbines the results are very similar to the 20 wind turbine wind farm. It can be seen that a larger number of wind turbines reduces the generated power. This effect can be overcome by appropriately clustering the wind turbines. 


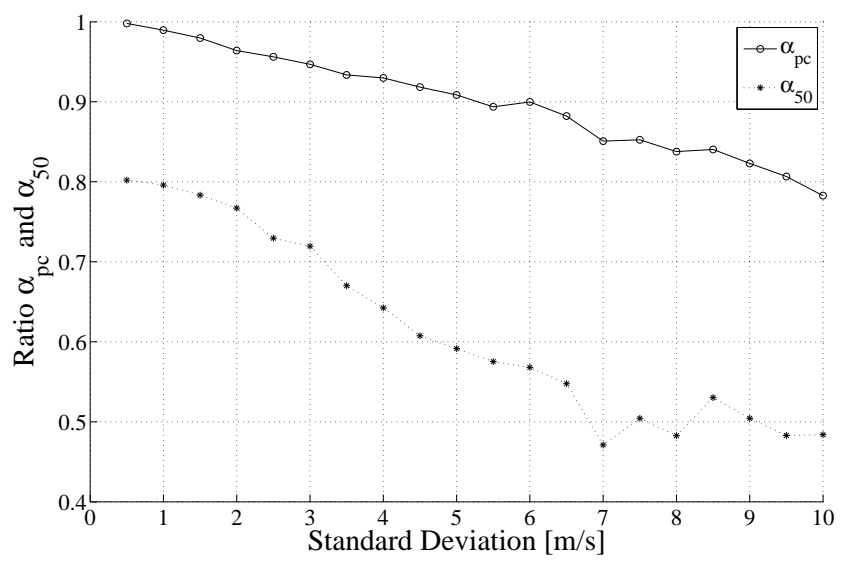

Fig. 1. Dependance of the ratios $\alpha_{p c}$ and $\alpha_{50}$ on the standard deviation of the wind speeds inside the wind farm

\section{OPTIMUM ELECTRICAL FREQUENCY SEARCH}

\section{A. Wind turbine power generation}

The power $P_{w t i}$ generated by a wind turbine can be written as $P_{w t i}=C_{p} P_{w i n d}=\frac{1}{2} C_{p} \rho A v_{w}^{3}$ where $P_{w i n d}$ is the air stream kinetic power, $\rho$ is the air density, $A=\pi R^{2}$ is the surface covered by the wind wheel of radius $R, v_{w}$ is the average wind speed and $C_{p}$ is the power coefficient, which can be written as [24]:

$$
C_{p}\left(\lambda, \theta_{\text {pitch }}\right)=c_{1}\left(c_{2} \frac{1}{\Lambda}-c_{3} \theta_{\text {pitch }}-c_{4} \theta_{\text {pitch }}^{c_{5}}-c_{6}\right) e^{-c_{7} \frac{1}{\Lambda}}
$$

where $\theta_{\text {pitch }}$ is the pitch angle and $\lambda$ is the so called tip speed ratio defined as $\lambda=\frac{\omega_{t} R}{v_{w}}$ where $\omega_{t}$ is the wind turbine speed and $\frac{1}{\Lambda}=\frac{1}{\lambda+c_{8} \theta_{\text {pitch }}}-\frac{c_{9}}{1+\theta_{\text {pitch }}^{3}}$ where $\left[c_{1} \ldots c_{9}\right]$ are characteristic constants for each wind turbine.

A typical $C p-\lambda$ curve is sketched in Fig. 2. The $C p-\lambda$ curve has a maximum value which corresponds to the optimum operating point of the wind turbine as long as the wind speed does not overcome the maximum threshold.

In a single wind turbine, the maximum $C_{P}$ is obtained [17], [18] when $T_{w t i}=K \omega_{t}^{2}$ ( $K$ depends on the coefficients $c_{i}$ ) which guarantees maximum power generation for a single wind turbine, but it cannot be directly applied to a whole wind farm with different wind speeds.

\section{B. Wind farm generation analysis}

The total power generated by a wind farm composed of $N_{w t}$ wind turbines can be expressed as $P_{w f}=\sum_{i=1}^{N_{w t}} P_{w t i}$. Without loss of generality, all the wind turbines can be considered identical and therefore all the wind turbine constants will keep the same values for all the wind farm. In this case, the total power generated $P_{w f}=\frac{1}{2} \rho A \sum_{i=1}^{N_{w t}} C_{P i} v_{w i}^{3}$, where it can be noted that $C_{P i}$ and $v_{w i}$ can be different for the different wind turbines and therefore it is not possible to operate all the machines at the optimum operating point except when they are all working with the same wind speed.

A typical example of a multi wind turbine wind farm is shown in Fig. 2. Four operation points for four wind turbines

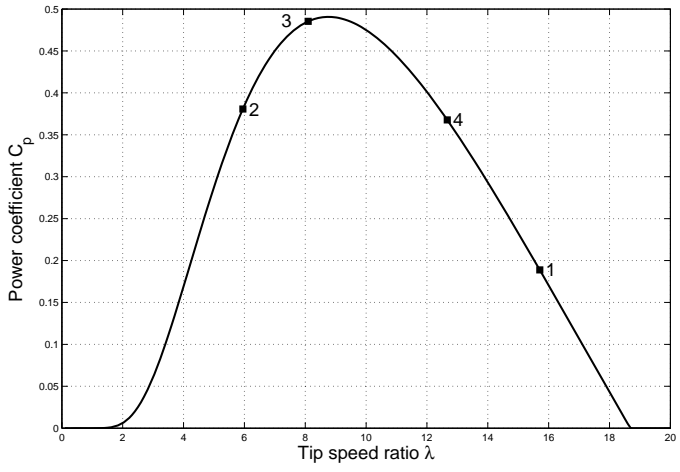

Fig. 2. $C_{p}-\lambda$ curve for different wind turbines generating with different wind speeds with electrical frequency of $50 \mathrm{~Hz}$. The wind turbine parameters of Appendix are used.

with different wind speeds are shown. The different wind speeds imply different $\lambda$ and $C_{p}$ and therefore it can be seen clearly that it is not possible to operate all the wind turbines at the maximum $C_{p}$. The four different wind turbine operating points correspond to the following data: $1 v_{w}=5 \mathrm{~m} / \mathrm{s}, C_{p}=$ $0.189, P_{\text {elec }}=0.0409 \mathrm{MW}, 2 v_{w}=13 \mathrm{~m} / \mathrm{s}, C_{p}=0.381, P_{\text {elec }}=$ $1.52 \mathrm{MW}, 3 v_{w}=9.7 \mathrm{~m} / \mathrm{s}, C_{p}=0.485, P_{\text {elec }}=0.767 \mathrm{MW}, 4$ $v_{w}=6.2 \mathrm{~m} / \mathrm{s}, C_{p}=0.368, P_{\text {elec }}=0.152 \mathrm{MW}$.

\section{Optimum electrical frequency search}

In order to generate the maximum possible energy in a wind farm, it is proposed to modify the electrical wind farm frequency and consequently the wind turbines speed. To find the electrical frequency that maximizes the total power of the wind farm (circular marker of Fig. 3), it is proposed to express the $C_{p}$ expression (1) as a polynomial of degree $N_{p o l}$ and coefficients $a_{j}$

$$
C_{p}(\lambda)=\sum_{j=0}^{N_{p o l}} a_{j} \lambda^{j}=\sum_{j=0}^{N_{p o l}} a_{j} \frac{\left(\omega_{t} R\right)^{j}}{v_{w}^{j}}
$$

where $\theta_{\text {pitch }}$ has been assumed to be the minimum value (zero) as the maximum power is to be extracted. The power generated by each turbine $i$ can be expressed as

$$
P_{w t-i}=\frac{1}{2} \rho A v_{w i}^{3} \sum_{j=0}^{N_{p o l}} a_{j} \frac{\left(\omega_{t} R\right)^{j}}{v_{w i}^{j}}
$$

For each synchronous generator, the wind turbine speed in steady state conditions can be written as $\omega_{t}=\frac{\omega_{e}}{P N_{m u l t}}$ where $\omega_{e}$ is the grid electrical angular speed, $P$ is the pole pairs number and $N_{\text {mult }}$ is the multiplier factor. Substituting it in expression (3), rearranging and summing all the wind turbine power, the total wind farm power yields

$$
P_{w f}=\frac{1}{2} \rho A \sum_{i=1}^{N_{w t}} \sum_{j=0}^{N_{p o l}} a_{j}\left(\frac{R}{P N_{\text {mult }}}\right)^{j} \omega_{e}^{j} v_{w i}^{3-j}
$$

To determine the electrical angular speed $\omega_{e}$ that maximizes the total generated power, one can evaluate $\frac{d P_{w f}}{d \omega_{e}}=0$ which 
can also be expressed as

$$
\sum_{j=1}^{N_{p o l}} b_{j} \omega_{e}^{j-1}=0, \quad b_{j}=\frac{1}{2} \rho A j a_{j}\left(\frac{R}{P N_{\text {mult }}}\right)^{j} \sum_{i=1}^{N_{w t}} v_{w i}^{3-j}
$$

Solving (5), $N_{p o l}-1$ solutions are found, the obtained real solutions can be substituted in the total power equation (4) in order to determine which is the optimal solution.

It is important to note that the computational time needed to solve (5) can be expressed as the sum of the time $T_{c o m-b j}$ needed to calculate the parameters $b_{j}$ and the time $T_{c o m-e q}$ needed to solve the equation. $T_{c o m-b j}$ can be expressed as $T_{c o m-b j}=N_{p o l} T_{b}$ where $T_{b}$ is proportional to the number of wind turbines $N_{w t}$. On the other hand, since the equation is a polynomial of degree $N_{p o l}-1$ with a single unknown $\omega_{e}$, $T_{\text {com }_{e} q}$ depends only on the degree of the polynomial and not in the number of wind turbines. Using a common computer, and considering $N_{p o l}=5$, the optimal frequency of a wind farm of 198 wind turbines can be calculated in approximately $100 \mathrm{~ms}$ and a wind farm of 1998 wind turbines in 1 second.

\section{Application example}

A wind farm composed of four wind turbines is analyzed, considering the parameters described in the Appendix.

The $C_{p}-\lambda$ curve has been approximated to the fifth degree polynomial $-8.08 \times 10^{-6} \lambda^{5}+0.00042 \lambda^{4}-0.0078 \lambda^{3}+$ $0.053 \lambda^{2}-0.024 \lambda-0.176$.

Wind speeds of $11.1 \mathrm{~m} / \mathrm{s}, 13 \mathrm{~m} / \mathrm{s}, 9.6 \mathrm{~m} / \mathrm{s}$ and $8.2 \mathrm{~m} / \mathrm{s}$ have been considered. Fig. 3 shows the power generated in the wind farm depending on the electrical grid frequency. The bold black line shows the power generated for different grid electrical frequencies, whose maximum is illustrated by a circular marker.

In order to determine the optimum electrical frequency, the parameters $b_{i}$ have been computed according to (5) as functions of the wind turbines parameters and the incoming wind speeds. The optimal electrical frequency can be computed solving the equation $-3.6570+0.4930 \omega_{e}-0.0035 \omega_{e}^{2}$

$+8.1861 \times 10^{-6} \omega_{e}^{3}-6.6126 \times 10^{-9} \omega_{e}^{4}=0$ whose solutions yield 467.95+j143.87, 467.95-j143.87, 294.21 and 7.84. Among these four solutions it is clear that the optimum $\omega_{e}$ is $294.21 \mathrm{rad} / \mathrm{s}$ (which corresponds to $47.05 \mathrm{~Hz}$ ), since two of the other roots are complex numbers and the other one corresponds to the minimum power. In a real time control system, the Newton iteration method can be used to rapidly compute the solution by choosing appropriate initial solutions such as $2 \pi 50 \approx 314.16 \mathrm{rad} / \mathrm{s}$.

\section{WIND FARM GRID CONNECTED TO A SINGLE POWER CONVERTER}

The proposed electrical scheme is sketched in Fig. 4. The wind farm is composed of wind turbines coupled to synchronous generators. Each generator is connected to the medium voltage farm grid by means of a transformer. A single power converter receives the power from all the turbines in order to rectify it and let the power flow through the HVDC link. Onshore, a HVDC-VSC inverter interfaces the HVDC link to the main AC grid.

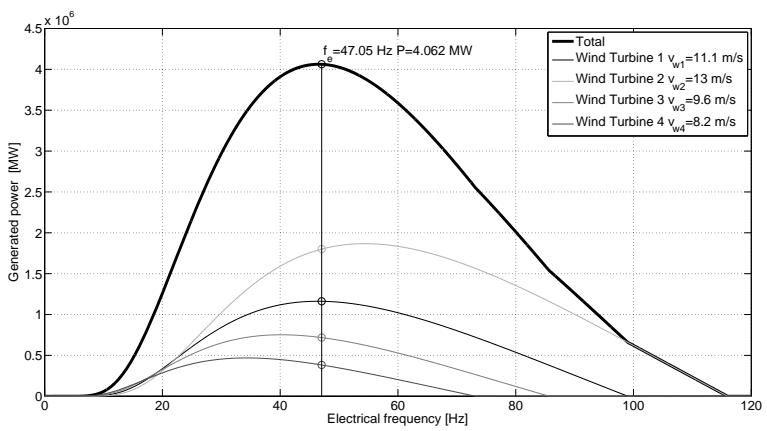

Fig. 3. Generated power depending on the electrical frequency in a wind farm with four wind turbines with different wind speeds

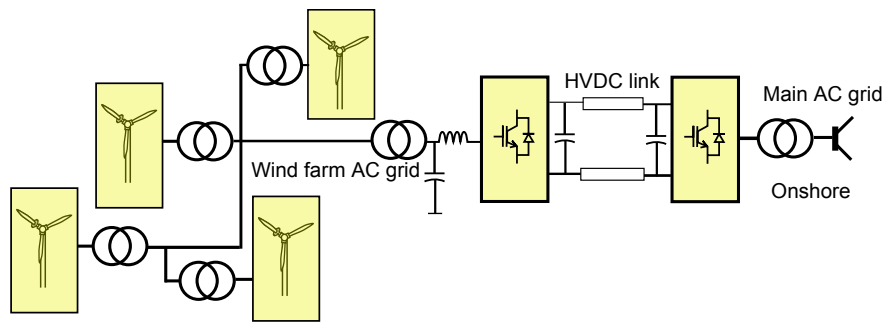

Fig. 4. Offshore wind farm connected to the main grid by means of HVDC

\section{A. Wind farm and power converter analysis}

The wind farm grid voltage and current is controlled by a single power converter which also is in charge of rectifying all the generated power and injecting it in the HVDC circuit. This power converter will also control the system frequency and generated active power. The considered power converter is a two-level boost rectifier equipped with an AC filter and a transformer for the wind farm grid.

Referring all the quantities to the generator low voltage grid and considering all the voltages and currents in the synchronous reference frame, the wind farm grid voltage equations can be written as:

$$
\left[\begin{array}{c}
v_{s q}-v_{c q} \\
v_{s d}-v_{c d}
\end{array}\right]=\left[\begin{array}{cc}
R_{l} & -L_{l} \omega_{e} \\
L_{l} \omega_{e} & R_{l}
\end{array}\right]\left[\begin{array}{l}
i_{s q} \\
i_{s d}
\end{array}\right]+\left[\begin{array}{cc}
L_{l} & 0 \\
0 & L_{l}
\end{array}\right] \frac{d}{d t}\left[\begin{array}{c}
i_{s q} \\
i_{s d}
\end{array}\right]
$$

where $v_{c}$ is the converter side voltage, $v_{s}$ is the wind farm voltage and $i_{s}$ is the total wind farm current. The power converter transformer is simplified as a RL branch with resistance $R_{l}$ and inductance $L_{l}$. Subindexes $q, d$ stand for quadrature and direct quantities in the synchronous reference frame.

Active and reactive power provided by the power converter can be written using instantaneous power theory as $P_{c}=$ $\frac{3}{2}\left(v_{s q} i_{s q}+v_{s d} i_{s d}\right)$ and $Q_{c}=\frac{3}{2}\left(v_{s q} i_{s d}-v_{s d} i_{s q}\right)$.

\section{B. Synchronous generator wind turbines}

Each wind turbine is based on a synchronous generator, attached to the wind wheel by means of a multiplier. The wind turbine has a pitch system to limit power, which is activated when the turbine speed overcomes a given threshold. The generator is connected to the wind farm grid by means of a transformer. 
In the present Section steady-state analysis is conducted with the system sketched in Fig. 5. The transient simulation analysis is developed in Section VI with complete transient models.

The power converter is represented in the steady state analysis as a voltage source with its voltage referred to the generator voltage. The synchronous generators are modelled as voltage sources with a series resistance and inductance.

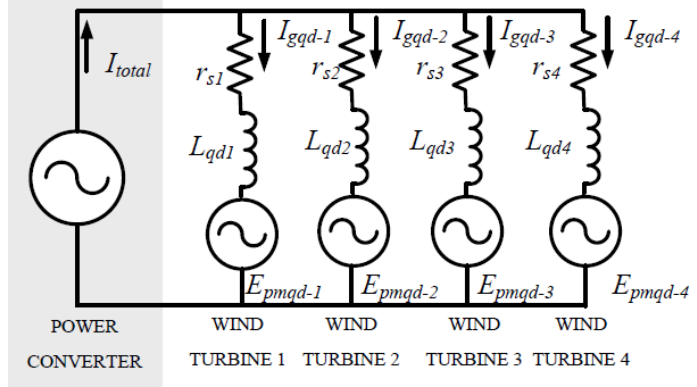

Fig. 5. Analyzed simplified system

For the case of permanent magnet synchronous generators (PMSG), the generator voltage equations in the synchronous reference frame $\left(\mathbf{V}_{g q d}=v_{g q}+0 j\right)$ for each wind turbine $i$ can be written as:

$$
\begin{aligned}
\mathbf{V}_{g q d}=\left[\begin{array}{cc}
r_{s} & P \omega_{r i} L_{q} \\
-P \omega_{r i} L_{d} & r_{s}
\end{array}\right] \mathbf{I}_{g q d-i} \\
+\left[\begin{array}{cc}
L_{q} & 0 \\
0 & L_{d}
\end{array}\right] \frac{d}{d t} \mathbf{I}_{g q d-i}+\mathbf{E}_{p m q d-i}
\end{aligned}
$$

where $\omega_{r i}$ is the generator $i$ mechanical speed, $\mathbf{I}_{g q d-i}$ is the generator $i$ current, $\mathbf{V}_{g q d}$ is the wind farm voltage which is assumed constant for all the generators, $r_{s}$ is the generator stator winding resistance, and $L_{q}$ and $L_{d}$ the generator inductances. The voltage $\mathbf{E}_{p m q d-i}$ generated by the permanent magnet flux yields

$$
\mathbf{E}_{p m q d-i}=\lambda_{m} P \omega_{r i}\left[\begin{array}{c}
\cos \theta_{i} \\
-\sin \theta_{i}
\end{array}\right]
$$

where $\lambda_{m}$ is the flux due to the rotor magnet, $P$ is the number of pairs of poles of the generator and $\theta_{i}$ is the angle between the rotor and the synchronous reference frame.

The generator torque yields $\Gamma_{e-i}=$ $\frac{3}{2} P\left(\lambda_{m} i_{g q-i}^{r}+\left(L_{d}-L_{q}\right) i_{g q-i}^{r} i_{g d-i}^{r}\right)$ where the currents $\mathbf{I}_{g q d-i}^{r}=i_{g q-i}^{r}+j i_{g d-i}^{r}$ are orientated with the generator rotor. For a surface mounted PMSG, $L_{q d}=L_{q}=L_{d}$ and the torque expression can be simplified $\Gamma_{e-i}=\frac{3}{2} P \lambda_{m} i_{g q-i}^{r}$. Considering the currents in the converter synchronous reference frame, the torque can be expressed as $\Gamma_{e-i}=\frac{3}{2} P \lambda_{m}\left(i_{g q-i} \cos \theta_{i}-i_{g d-i} \sin \theta_{i}\right)$. The steady state equations of the system can be written using (7), assuming that all the generators speeds are equal $\omega_{r i}=\omega_{e} / P$ and considering $d \mathbf{I}_{g q d-i} / d t \approx 0$

$$
\begin{gathered}
v_{g q}+0 j=\left[\begin{array}{cc}
r_{s} & \omega_{e} L_{q d} \\
-\omega_{e} L_{q d} & r_{s}
\end{array}\right] \mathbf{I}_{g q d-i}+\lambda_{m} \omega_{e}\left[\begin{array}{c}
\cos \theta_{i} \\
-\sin \theta_{i}
\end{array}\right] \\
\Gamma_{e-i}=\frac{3}{2} P \lambda_{m}\left(i_{g q-i} \cos \theta_{i}-i_{g d-i} \sin \theta_{i}\right)
\end{gathered}
$$

where there are $3 N_{w t}$ equations and the $3 N_{w t}$ unknown quantities are $N_{w t}$ angles $\theta_{i}, N_{w t}$ currents $i_{g q-i}$ and $N_{w t}$ currents $i_{g d-i}$.

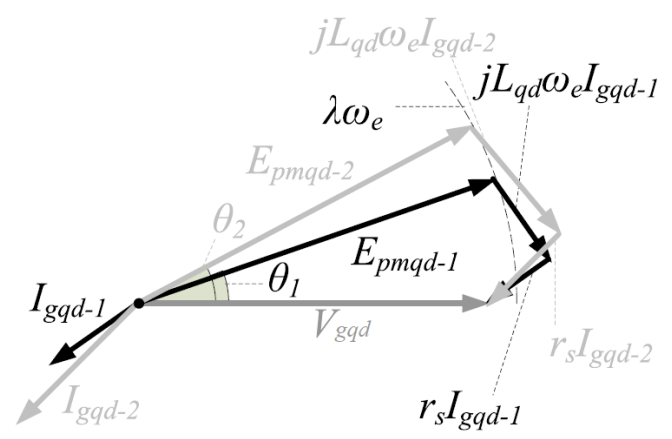

Fig. 6. Phasor representation of a two generator system

A phasor diagram with two generators is illustrated in Fig. 6. It can be seen that the angle $\theta_{i}$ is adjusted to accommodate the different power generation between the different wind turbines; the larger the angle, the larger the generated power. The module of the vectors $E_{p m q d-i}$ is kept constant since all the generators rotate at identical mechanical speed.

\section{Control SCHEME}

The system is controlled separately by two noncommunicating systems. Onshore, the power converter controls the HVDC voltage by injecting all the incoming power to the main AC grid. Offshore, the power converter seeks the maximum power generation in normal conditions and maintains HVDC voltage reducing the generated power if the onshore converter cannot extract all the available power, for example in the event of a voltage sag in the main AC grid.

\section{A. Onshore converter}

The onshore converter is responsible for the HVDC voltage control and the support to the main AC grid. The VSC converter can control independently active and reactive power. Active power is adjusted to control the HVDC voltage while reactive power is usually used to provide voltage support to the grid. When a fault in the AC grid occurs, the power converter can continue operating but its power injection capability is

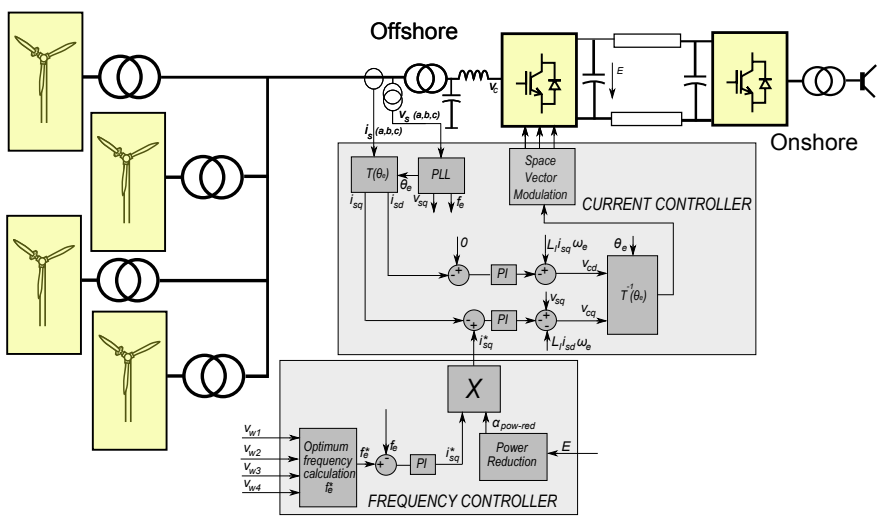

Fig. 7. Proposed control scheme 
dramatically reduced. In this case, it switches its operating mode and enters a current control mode (to protect the power converter) instead of HVDC voltage control mode, implying a HVDC voltage increase until the offshore power converter can take over the voltage control and maintain system stability.

\section{B. Offshore converter}

The proposed system control scheme is illustrated in Fig. 7. The control structure is composed of two different levels: the frequency controller and the current controller. The frequency controller is slower than the lower level fast current controller.

1) Frequency controller: The higher level controller is responsible for the wind farm electrical frequency control and HVDC voltage control in the event of faults. It has three operation modes:

- Normal operation mode: The HVDC voltage is controlled by the onshore power converter. Offshore, the wind speed is measured in each wind turbine. The central frequency controller receives the measurements from all wind turbines and computes the optimum electrical frequency according to (5). A controller regulates the system electrical frequency to the reference value by adjusting the power converter $i_{s q}^{*}$ current, which is proportional to the extracted active power. The frequency controller is adjusted to be a slow loop in order to guarantee system stability. The wind turbine pitch angle is maintained in the minimum angle in this operation mode.

- Maximum frequency mode: There is a maximum electrical frequency which corresponds to the maximum mechanical wind turbines speed. When this frequency is reached, the electrical frequency will be kept constant, and the wind turbines will locally limit their injected power adjusting the pitch angle.

- Power limiting mode: When there is a fault in the main AC grid, the onshore power converter can dramatically reduce its extraction power capability. In this case, the onshore power converter cannot control the HVDC voltage and the offshore power converter deals with this task. Since there are no communications between the two power converters, the only way of detecting the abnormal situation is with the HVDC voltage $E$. When $E$ overcomes a given threshold $E_{L-\text { pow-red }}$, the computed $i_{s q}^{*}$ reference current is modified with the factor $\alpha_{\text {pow-red }}$, which is expressed as

$$
\alpha_{\text {pow-red }}=1-k_{\text {pow-red }}\left(E-E_{L-\text { pow-red }}\right)
$$

where $\alpha_{\text {pow-red }}$ is limited between 0 and 1 .

The frequency PI controller can be designed as the control of the rotation speed of an aggregated wind turbine which accumulates the inertia and mechanical torque of the whole wind farm. Using [25], the PI controller can be expressed as $K_{n}+\frac{K_{n}}{s \tau_{n}}$, where $K_{n}=\frac{J_{a g}}{2 \tau}$ and $\tau_{n}=20 \tau$, where $J_{a g}=\frac{N_{w t} J}{\left(P N_{m u l t}\right)^{2}}$ is the aggregated equivalent inertia of all the turbines considered and $\tau$ is the time constant of the current loops.
2) Current controller: The power converter voltage and current are measured in the medium voltage grid. A phaselocked loop (PLL) is employed to generate the synchronous reference frame angle $\theta_{e}$ and determine the electrical angular speed $\omega_{e}$ and voltages $v_{s q}$ (note that $v_{s d}=0$ ).

Using the instantaneous power theory [26] with the selected rotating reference frame $\left(v_{s d}=0\right)$ the current reference can be calculated

$$
i_{s q}^{*}=\frac{2 P_{c}^{*}}{3 v_{s q}}, i_{s d}^{*}=\frac{2 Q_{c}^{*}}{3 v_{s q}}
$$

where $Q_{c}^{*}$ will usually be 0 in order to minimize the wind farm current. It can be seen in Fig. 7 that the higher level control supplies directly the current reference $i_{s q}^{*}$ which is equivalent to supplying the power reference $P_{c}^{*}$.

The current control is done by the following state linearization feedback [3]:

$$
\left[\begin{array}{c}
v_{c q} \\
v_{c d}
\end{array}\right]=\left[\begin{array}{c}
-\hat{v}_{c q}+v_{s q}-L_{l} \omega_{e} i_{s d} \\
-\hat{v}_{c d}+L_{l} \omega_{e} i_{s q}
\end{array}\right]
$$

where the $\hat{v}_{c q}$ and $\hat{v}_{c d}$ are the output voltages of the PI current controller.

The PI controllers have been designed using the so-called internal model control (IMC) methodology detailed in [27]. The parameters of a PI controller to obtain a desired time constant $\tau$ are obtained as $K_{p}=\frac{L}{\tau}$ and $K_{i}=\frac{R}{\tau}$. The currents and voltages have been limited according to the converter operating limits. PI controllers have been designed with anti-windup in order to prevent control instabilities when the controller exceed the limit values.

\section{Simulation Results}

The proposed control scheme has been tested with a four 2 MW wind turbine wind farm by means of simulations using Matlab Simulink ${ }^{\circledR}$. The wind farm is connected to a HVDC circuit with a full power HVDC-VSC converter. Onshore, another HVDC-VSC interfaces the HVDC circuit to the main grid. Wind turbine, generator, gearbox and grid parameters from typical wind turbine components [24] have been employed. Simulation parameters are shown in the Appendix.

\section{A. Normal operation with different wind speeds}

Simulations with four different varying winds for each wind turbine have been performed. The different wind speeds are illustrated in Fig. 8. The system has been simulated with different winds for each machine in order to evaluate the system performance with a single power converter.

The optimal calculated electrical frequency is shown in Fig. 8, where it can be seen that it is changing depending on the different wind speed measurements. The frequency controller regulates smoothly the system to the desired value by modifying the power converter current $i_{s q}^{*}$. The electrical frequency evolution is slow in order to guarantee system stability. The power converter current loops are illustrated in Fig. 8, a good tracking of both $i_{s q}^{*}$ and $i_{s d}^{*}$ can be observed.

The generators electrical power and torque are shown in Fig. 8. After an initial transient, both torque and power change according to the overall power converter power. It can be noted 

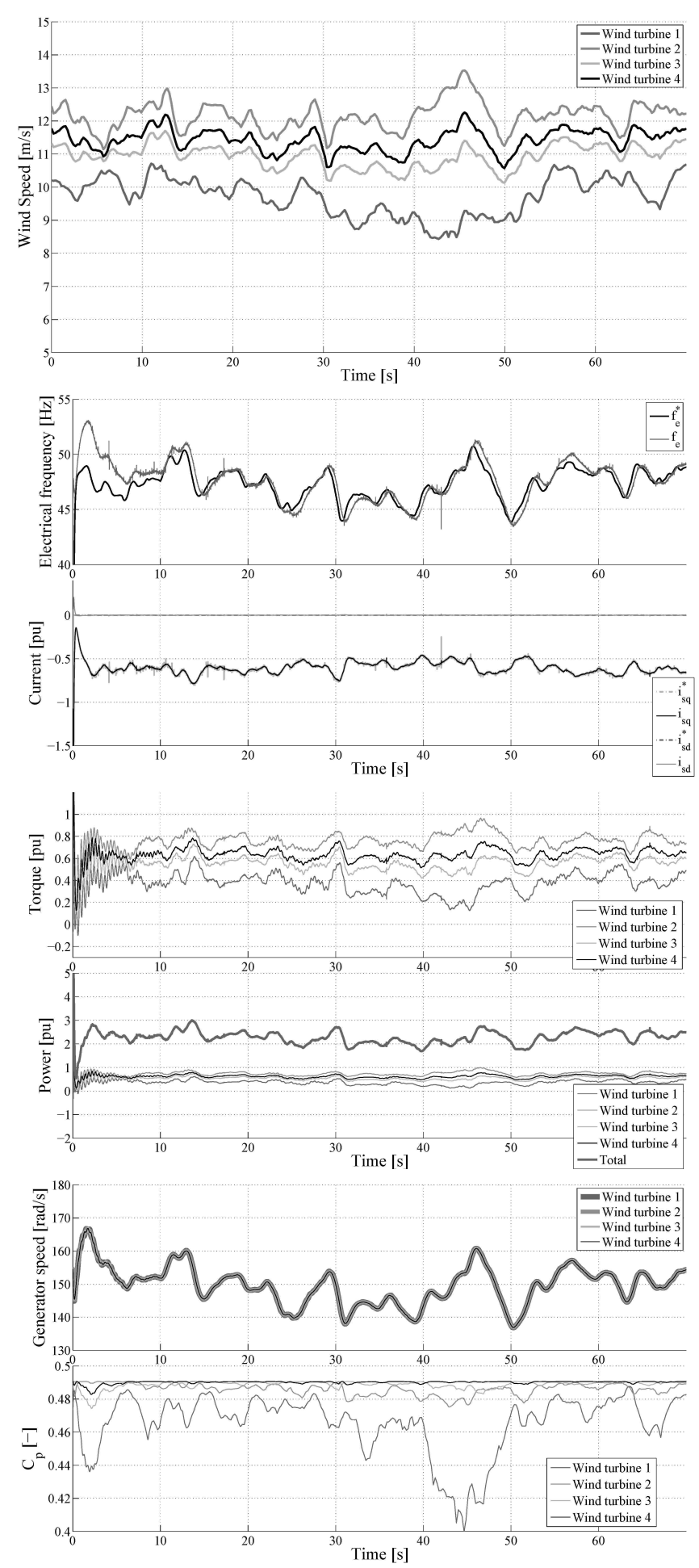

Fig. 8. Simulation results for normal operation with different wind speeds that each wind turbine generates a different amount of torque and power depending on the incoming wind.

The generator speeds and $C_{p}$ coefficients are shown in Fig. 8. After small oscillations in the initial transient, all the generator speeds are equal. It can be noted that $C_{p}$ values are maintained at high values, although it is not possible with a single converter to have the four wind turbines at maximum $C_{p}$ value.

\section{B. Operation with maximum frequency}

Simulations with a wind abrupt changes for each wind turbine have been performed. The wind speed of the four wind turbines is increased in order to test the operation of the system for high winds. The different wind speeds are illustrated in Fig. 9.

The optimal calculated electrical frequency and the current loops are shown in Fig. 9, where it can be seen that the system responds smoothly to the wind speed increase. The generators electrical power, torque and speed are shown in Fig. 9. It can be seen, that after a transient, stable steady state points are obtained.

The simulation shows that the system is operated at constant maximum frequency. The individual wind turbines reduce the power injected by employing the pitch system.

\section{Fault ride-through}

A fault in the main AC grid has been simulated in order to check the overall system behavior. The fault is produced at the time instant $5 \mathrm{~s}$ and lasts $500 \mathrm{~ms}$, implying a three phase voltage sag of $20 \%$ of the nominal voltage. It can be seen in Fig. 10 that once the HVDC voltage overcomes the threshold $E_{L-\text { pow-red }}$, the offshore power converter takes over the HVDC voltage control and maintains it stable by reducing the active power generation. This reduction implies the turbines speed increase and electrical frequency increase. Once the fault is cleared, the power converter returns to the electrical frequency control mode, and increases the generated power. A delay of about $33 \mathrm{~ms}$ can be observed between the fault and the reaction of the power converter. This delay occurs because the power reduction is triggered when the HVDC voltage overcomes the threshold $E_{L-\text { pow-red }}$ and this occurs 33 miliseconds after the fault.

In the case that the turbine speed would reach the maximum allowed value, the pitch system would respond incrementing the pitch angle and reducing generated power.

\section{CONCLUSIONS}

A control scheme for wind farms based on synchronous generators connected to a single power converter has been presented. The proposed control system can be applied to wind farms interfaced to the main AC grid by means of HVDC-VSC technology.

Depending on the different wind speeds in the wind turbines, an optimum electrical frequency is calculated. The power converter regulates the measured electrical frequency to this reference value by modifying the active power injected 

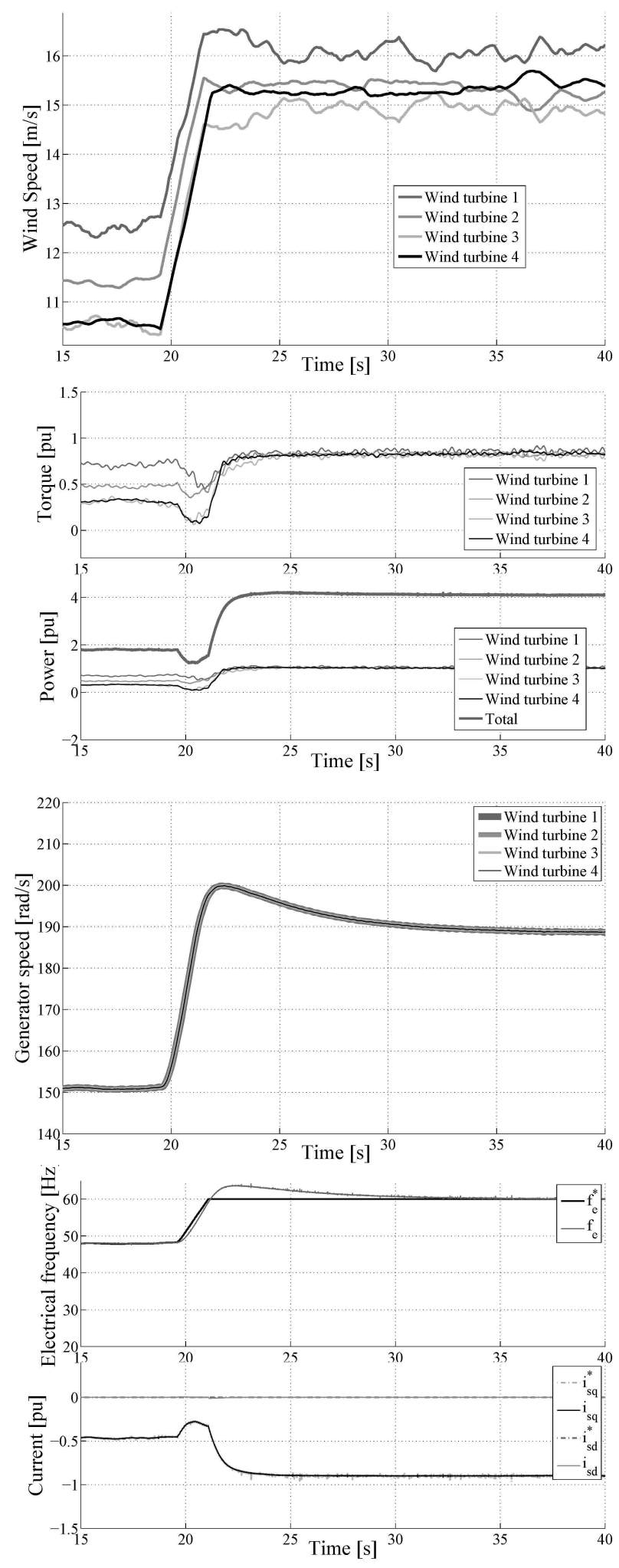

Fig. 9. Simulation results for wind speeds increase
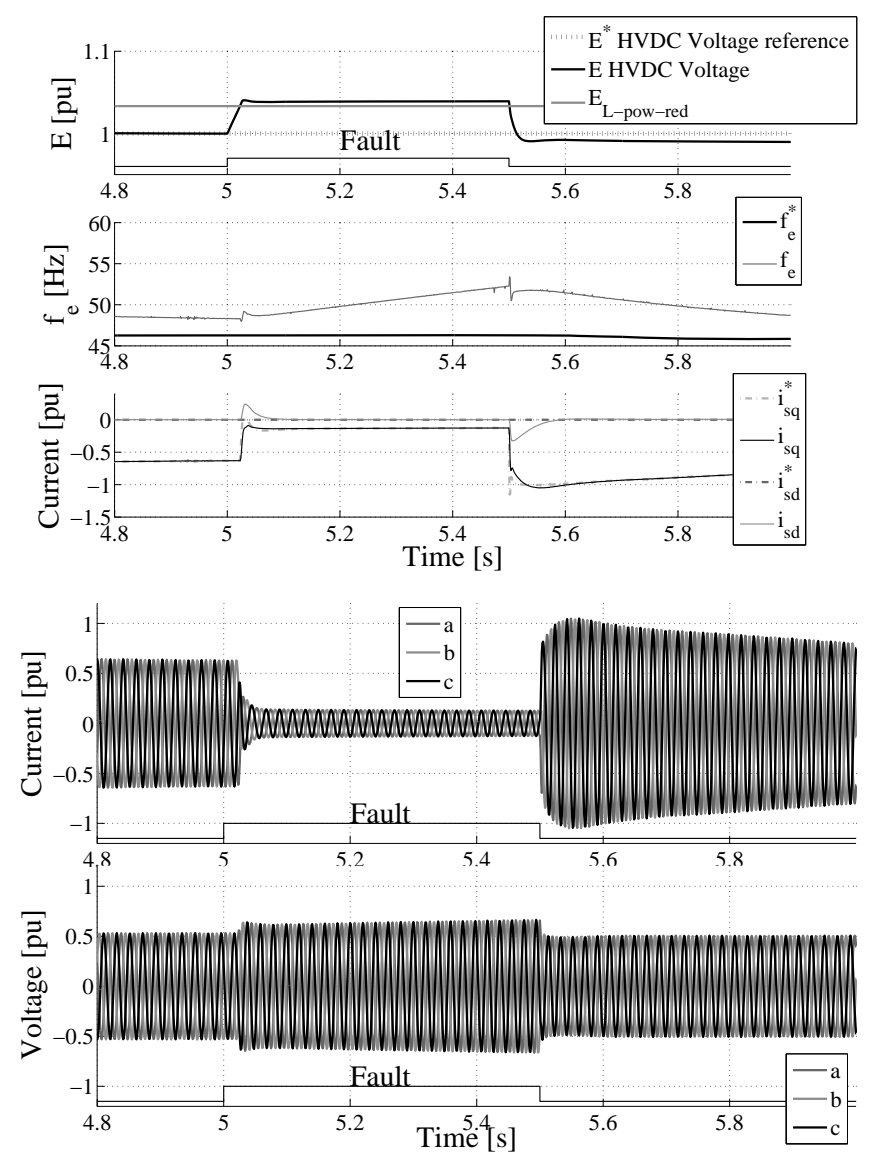

Fig. 10. Simulation results under a fault in the main AC grid

in the HVDC circuit. Fault ride-through capability is achieved with the reduction of the injected active power when a fault onshore occurs.

The proposed scheme has been validated with dynamic simulations, considering different wind speed operation and faults in the main AC grid.

\section{APPENDIX}

A wind farm composed of four wind turbines is considered. The employed wind turbine has a radius of 30 meters and a multiplier with $N_{\text {mult }}=45$. Air density is assumed 1.225 $\mathrm{kg} \mathrm{m}^{-3}$. The power coefficient $C_{p}$ is computed for all the turbines with $c_{1}=0.44, c_{2}=125, c_{6}=6.94, c_{7}=16.5$ and $c_{9}=-0.003$. A virtual resistance [28] has been added to the HVDC cable to model the losses in the power converter. The HVDC system has capacitors of $20 \mu \mathrm{F}$ in each side and voltage of $150 \mathrm{kV}$. A wind farm with four wind turbines rated to $2 \mathrm{MW}$ is considered. The base voltages are $110 \mathrm{kV}$ in the power converter $\mathrm{AC}$ side, $25 \mathrm{kV}$ in the medium voltage wind farm grid and $1000 \mathrm{~V}$ in the generators. The generators are permanent magnet synchronous generators with parameters are $R_{s}=0.01 \Omega, L_{q d}=1.65 \times 10^{-4} \mathrm{H}, \lambda=2.5 \mathrm{~Wb}$ and 2 pairs of poles. The controller parameters are $K_{n}=246.91$ and $\tau_{n}=4$ for the frequency controller, and $k_{p}=0.125 k_{i}=6.25$ for the current loops. The simulations have been performed with Matlab Simulink ${ }^{\circledR}$ using the ode15s solver. 


\section{REFERENCES}

[1] N. Ullah, K. Bhattacharya, and T. Thiringer, "Wind farms as reactive power ancillary service providers technical and economic issues," IEEE Transactions on Energy Conversion, vol. 24, pp. 661-672, 2009.

[2] Z. Miao, L. Fan, D. Osborn, and S. Yuvarajan, "Control of dfigbased wind generation to improve interarea oscillation damping," IEEE Transactions on Energy Conversion, vol. 24, pp. 415- 422, 2009.

[3] O. Gomis-Bellmunt, A. Junyent-Ferré, A. Sumper, and J. BergasJané, "Ride-through control of a doubly fed induction generator under unbalanced voltage sags," IEEE Transactions on Energy Conversion, vol. 23, no. 4, pp. 1036-1045, 2008.

[4] A. Sumper, O. Gomis-Bellmunt, A. Sudria-Andreu, R. VillafafilaRobles, and J. Rull-Duran, "Response of fixed speed wind turbines to system frequency disturbances," IEEE Transaction on Power Systems, vol. 24, pp. 181-192, 2009.

[5] L.-R. Chang-Chien and Y.-C. Yin, "Strategies for operating wind power in a similar manner of conventional power plant," IEEE Transactions on Energy Conversion, vol. 24, pp. 926-934, 2009.

[6] N. B. Negra, J. Todorovic, and T. Ackermann, "Loss evaluation of HVAC and HVDC transmission solutions for large offshore wind farms," Electric Power Systems Research, vol. 76, no. 11, pp. 916-927, 2006.

[7] J. Arrillaga, High Voltage Direct Current Transmission, 2nd ed. London, U.K.: Institution of Electrical Engineers, 1998.

[8] S. Bozhko, G. Asher, R. Li, J. Clare, and L. Yao, "Large offshore DFIGbased wind farm with line-commutated HVDC connection to the main grid: Engineering studies," IEEE Transaction on Energy Conversion, vol. 23, no. 1, pp. 119-127, 2008.

[9] D. Xiang, L. Ran, J. Bumby, P. Tavner, and S. Yang, "Coordinated control of an HVDC link and doubly fed induction generators in a large offshore wind farm," IEEE Transactions on Power Delivery, vol. 21, no. 1 , pp. 463-471, 2006.

[10] T. Ackermann, "Transmission systems for offshore wind farms," IEEE Power Engineering Review, vol. 22, no. 12, pp. 23-27, Dec. 2002.

[11] L. Xu and B. Andersen, "Grid connection of large offshore wind farms using HVDC," Wind Energy, vol. 9, no. 4, pp. 371-382, 2006.

[12] L. Xu, L. Yao, and C. Sasse, "Grid integration of large DFIG-based wind farms using VSC transmission," IEEE Transactions on Power Systems, vol. 22, no. 3, pp. 976-984, 2007.

[13] T. Vrionis, X. Koutiva, N. Vovos, and G. Giannakopoulos, "Control of an HVDC link connecting a wind farm to the grid for fault ride-through enhancement," IEEE Transactions on Power Systems, vol. 22, no. 4, pp. 2039-2047, 2007.

[14] D. Jovcic, "Offshore wind farm with a series multiterminal CSI HVDC," Electric Power Systems Research, vol. 78, pp. 747-755, 2008.

[15] D. Jovcic and N. Strachan, "Offshore wind farm with centralised power conversion and DC interconnection," IET Generation, Transmission and Distribution, vol. 3, pp. 586-595, 2009.

[16] M. Chinchilla, S. Arnaltes, and J. C. Burgos, "Control of permanentmagnet generators applied to variable-speed wind-energy systems connected to the grid," IEEE Transactions on Energy Conversion, vol. 21, pp. $130-135,2006$.

[17] D. Goodfellow and G. Smith, "Control strategy for variable speed of a fixed-pitch wind turbine operating in a wide speed range," in Proc. of 8th BWEA Conference, Cambridge, 1986, pp. 219-228.

[18] R. Pena, J. J.C. Clare, and G. Asher, "Doubly fed induction generator using back-to-back PWM converters and its application to variable-speed wind-energy generation," IEE Proceedings Electric Power Applications, vol. 143, no. 3, pp. 231-241, 1996.

[19] C. Feltes, H. Wrede, F. Koch, and I. Erlich, "Enhanced fault ride-through method for wind farms connected to the grid through VSC-based HVDC transmission," IEEE Transactions on Power Systems, vol. 24, pp. 1537 - 1546, 2009.

[20] R. L. Hendriks, R. Volzke, and W. L. Kling, "Fault ride-through strategies for vsc-connected wind parks," in EWEC2009 European Wind Energy Conference, Marseille, France, 2009, pp. 1-6.

[21] R. Barthelmie and S. Pryor, "Can satellite sampling of offshore wind speeds realistically represent wind speed distributions?" Journal of Applied Meteorology, vol. 42, pp. 83-94, 2003.

[22] S. Pryor, M. Nielsen, R. Barthelmie, and J. Mann, "Can satellite sampling of offshore wind speeds realistically represent wind speed distributions? part ii: Quantifying uncertainties associated with distribution fitting methods," Journal of Applied Meteorology, vol. 43, pp. 739-750, 2004.

[23] P. Soerensen, A. D. Hansen, F. Iov, F. Blaabjerg, and M. H. Donovan, "Risoe-r-1464 wind farm models and control strategies," Risoe, Tech. Rep., 2005.

[24] Z. Lubosny, Wind Turbine Operation in Electric Power Systems. Springer, 2003.

[25] G. Terörde, Electrical Drives and Control Techniques, 1st ed. Uitgeverij Acco, 2004

[26] H. Akagi, Y. Kanazawa, and A. Nabae, "Instantaneous reactive power compensators comprising switching devices without energy storage components," IEEE Transaction on Industry Applications, vol. 20, pp. 625-631, 1984

[27] L. Harnefors and H.-P. Nee, "Model-based current control of ac machines using the internal model control method," IEEE Transactions on Industry Applications, vol. 34, no. 1, pp. 133-141, Jan.-Feb. 1998.

[28] H. Xie, L. Ängquist, and H.-P. Nee, "Design and analysis of a controller for a converter interface interconnecting an energy storage with the DC link of a VSC,' IEEE Transactions on Power Systems, vol. 25, pp. 10071015,2010 